\title{
PERCEPÇÕES E MOTIVAÇÕES DE AGENTES COMUNITÁRIOS DE SAÚDE SOBRE O PROCESSO DE TRABALHO EM TERESINA, PIAUÍ
}

\author{
COMMUNITY HEALTH AGENTS PERCEPTIONS AND MOTIVATIONS ABOUT THE LABOR PROCESS \\ IN TERESINA, PIAUÍ
}

\author{
Elaine Monteiro da Costa ${ }^{1}$ \\ Danyege Lima Araújo Ferreira ${ }^{2}$
}

Resumo O agente comunitário de saúde (ACS) é considerado importante na implementação do Sistema Único de Saúde (SUS), especialmente por fortalecer a Atenção Básica. Seu trabalho pode ter situações que gerem realização e experiências que condicionem a desmotivação. Este estudo objetiva caracterizar o processo de trabalho dos ACS de um território de Teresina, Piauí descrevendo suas percepções e identificando suas motivações em relação ao trabalho. Participaram do estudo 31 ACS. Trata-se de um estudo exploratório-descritivo com abordagem qualitativa. Para coleta de dados utilizou-se o método grupo focal, realizando-se seis grupos, um por equipe de saúde da família pertencente ao território. As discussões foram baseadas em três perguntas norteadoras, gravadas em MP4 e, posteriormente, transcritas e categorizadas. Criaram-se cinco categorias para apresentação e discussão dos resultados. Percebeu-se que, entre os ACS, há o entendimento sobre a importância do trabalho que realizam, contudo se sentem desmotivados por não receberem apoio e reconhecimento, em determinadas situações, da comunidade, da própria equipe e da gestão do município. Os agentes comunitários de saúde anseiam pela valorização do trabalho realizado. Palavras-chave agente comunitário de saúde; Saúde da Família; processo de trabalho.
Abstract Community health agents (CHAs) are considered important for the implementation of the SUS (Sistema Único de Saúde/Single Health System), especially for reinforcing primary health care. Their work may lead to situations that generate realization and/or experiences that are determining for motivation. This study aims to characterize the labor process of the CHAs in an area of Teresina, State of Piauí, Brazil, describing their perceptions about work and their motivations. Thirty-one CHAs took part in the study. This is an exploratory and descriptive qualitative review. In order to collect data, we used the focus group method. Six focus groups were held, one per family health team belonging to the territory. The discussions were based on three guiding questions, recorded in MP4, and then transcribed and categorized. Five categories were created to present and discuss the results. It was noticed that the CHAs have an understanding of the importance of their work, but they feel discouraged for not getting support and recognition, in certain situations, from the community, the team itself, and from the city's management. There is a desire for the appreciation of their work.

Keywords community health agent; family health care; work process. 


\section{Introdução}

A saúde pública no Brasil, até meados da década de 1970, caracterizavase por ações pontuais voltadas para o combate às endemias. A partir de então, são trazidas para o debate político as primeiras propostas de reorganização do sistema de saúde brasileiro. Começa a se constituir uma série de programas com a finalidade de expandir os serviços de atenção primária (Vasconcelos, 2000).

Surge o movimento denominado Reforma Sanitária, cujas propostas foram amplamente discutidas por ocasião da VIII Conferência Nacional de Saúde, e suas repercussões culminaram com o artigo 196 da Constituição de 1988, estabelecendo a saúde como direito de todos e dever do Estado. Com a aprovação da lei n. 8.080, complementada pela lei n. 8.142, em 1990, consolida-se o Sistema Único de Saúde (SUS), sob responsabilidade das três esferas governamentais (Brasil, 1997).

De acordo com Vasconcelos (2000), os anos 90 do século passado trouxeram para o setor saúde uma revalorização do tema família. E é nesse cenário que surge o profissional agente comunitário de saúde (ACS), com a implantação do Programa de Agentes Comunitários de Saúde (Pacs), em 1991. Formulado pelo Ministério da Saúde, o programa visava a contribuir para a redução das mortalidades infantil e materna, por meio da extensão de ações de saúde (Rosa e Labate, 2005).

Em 1994, o Pacs ganha um redimensionamento com a formação das primeiras equipes do Programa Saúde da Família (Velloso, 2005). Assim, a equipe mínima passa a ser composta pelos profissionais médico, enfermeiro, auxiliar ou técnico de enfermagem e ACS, e a equipe ampliada conta ainda com os profissionais cirurgião- dentista, auxiliar de consultório dentário e/ou técnico em higiene dental (Brasil, 2007).

Posteriormente, o programa passa a se chamar Estratégia Saúde da Família (ESF) e se apresenta como a nova maneira de trabalhar a saúde, tendo a família como centro de atenção, facilitando a aproximação e a criação de vínculos entre profissionais e pessoas. A equipe assume responsabilidade por um território específico e os sujeitos inseridos nele, e deve agir promocional e preventivamente no controle de causas, riscos e danos, atuando num novo modelo de intervenção (Rosa e Labate, 2005).

Atualmente, 204 mil ACS estão em atuação no país (Brasil, 2011). A identidade desses profissionais se constrói em situações concretas do seu trabalho, na relação com a população e com os demais integrantes da equipe (Silva e Dalmaso, 2002). E no exercício desse trabalho, algumas situações vivenciadas por eles, como responsabilidade pela mudança do paradigma biomédico e trabalho em equipe fragmentado, provocam certo 'sofrimento' em relação à sua prática, causando problemas de saúde, desmotivação e insatisfação na execução das ações (Lunardelo, 2004). 
Em experiência como residente de enfermagem e tutora do Programa de Residência Multiprofissional em Saúde da Família e Comunidade (RMSFC) da Universidade Estadual do Piauí (Uespi), convivendo de perto com os ACS de um território específico do município de Teresina, percebeu-se a desmotivação de grande parte desses profissionais em relação ao seu trabalho. Isso nos levou a investigar as razões que provocam o desestímulo desses atores tão importantes para a efetivação da ESF.

Esta pesquisa teve como objetivo geral caracterizar o processo de trabalho dos ACS atuantes no território Planalto Uruguai e Vila Santa Bárbara da ESF do município de Teresina (PI) e, como objetivos específicos, descrever a percepção dos ACS em relação ao seu processo de trabalho na ESF e identificar as motivações desses profissionais.

\section{Metodologia}

A pesquisa em questão é um estudo exploratório-descritivo com abordagem qualitativa. Segundo Gil (2009), a pesquisa exploratória objetiva o aprimoramento de ideias; a pesquisa descritiva vem descrever as características de determinada população ou fenômeno. E a abordagem qualitativa tem como peculiaridade utilizar-se da subjetividade para trabalhar questões que não podem ser simplesmente quantificadas (Minayo, 2003).

O estudo foi realizado com ACS das equipes de Saúde da Família atuantes no território citado anteriormente, pertencentes à Regional Leste/Sudeste (Fundação Municipal de Saúde-FMS) do município de Teresina, Piauí. Este território possui seis equipes, sendo quatro no Planalto Uruguai e duas na Vila Santa Bárbara. Por equipe, o número de ACS varia entre seis e sete, totalizando quarenta agentes em todo o território.

Para a coleta de dados, utilizou-se o método grupo focal. Este consiste numa técnica de pesquisa em que o investigador reúne, num mesmo local e período, uma determinada quantidade de pessoas que compõem o público-alvo de suas investigações, objetivando coletar informações sobre o tema definido mediante o diálogo com e entre eles (Cruz Neto, Moreira e Sucena, 2002).

Desse modo, foram realizados seis grupos, um por equipe, nos meses de maio e junho de 2010, com as entrevistas gravadas em MP4 com as seguintes perguntas norteadoras: como vocês se sentem trabalhando numa equipe de Saúde da Família? Quais as vantagens e desvantagens de se trabalhar em equipe? O que motiva vocês no processo de trabalho?

Da amostra total, 31 agentes participaram do estudo. Os demais não compareceram, excluindo-se, portanto, a participação.

Assim, os sujeitos participantes foram 25 ACS do sexo feminino e seis do sexo masculino, com idades entre vinte e cinquenta anos. A formação 
deles englobou desde o ensino médio completo ao ensino superior com pósgraduação. E o tempo de serviço na ESF variou entre um mês e 14 anos.

Posteriormente, o conteúdo das discussões foi transcrito, analisado e organizado por similaridade de respostas - categorização. O trabalho com categorias agrupa elementos e ideias em torno de um conceito (Minayo, 2003). Foram criadas cinco categorias para apresentação dos resultados encontrados: ACS - percepção sobre o trabalho na equipe de Saúde da Família; a relação com a comunidade; vantagens e desvantagens do trabalho em equipe; interação entre gestão e equipe Saúde da Família; e as (des)motivações do cotidiano do trabalho.

A pesquisa foi submetida à autorização da Instituição FMS e à aprovação pelo Comitê de Ética e Pesquisa da Faculdade Integral Diferencial/Integral Grupo de Ensino Fundamental, Médio, Técnico e Superior do Piauí S/C Ltda. (Facid).

Seguindo as normas que regulamentam a pesquisa em seres humanos, resolução n. 196/96 do Conselho Nacional de Saúde (Brasil, 1996), os sujeitos participantes assinaram o Termo de Consentimento Livre e Esclarecido, atendendo aos aspectos éticos, respeitando-se o anonimato. Com a finalidade de preservar a identidade, seus nomes foram substituídos por nomes de flores, definidos pela autora do estudo.

\section{Resultados e discussão}

\section{ACS: percepção sobre o trabalho na equipe de Saúde da Família}

Esta categoria descreve como os ACS percebem o desenvolvimento do seu trabalho e o da equipe, e quais as sensações e os reflexos que eles promovem em sua vida profissional e pessoal.

A inserção de uma equipe multiprofissional no processo de cuidado à saúde possibilita organizar o trabalho com um nível de complementaridade e, ao mesmo tempo, de especificidade, para melhor atender aos anseios e necessidades da população (Moysés et al., 1999). Os ACS são selecionados nas áreas onde serão desenvolvidas as ações da Estratégia Saúde da Família. Seoane e Fortes (2009) destacam que essa ligação com a realidade da comunidade possibilita o fortalecimento do vínculo entre profissionais e sujeitos. Os relatos dos ACS traduzem a satisfação pessoal em poder contribuir para a melhoria da saúde de sua comunidade.

Eu me sinto realizado como pessoa. (...) Me dá satisfação em ver o bem da comunidade (Lírio). 
A gente se sente muito também em tá fazendo alguma coisa pra melhorar a saúde da população. (...) A gente funciona como uma referência (Açucena).

Sua colaboração para levar a equipe de trabalho para ações diretas na comunidade tem contribuído para a melhoria da qualidade dos serviços. O cuidado passa a ser mais que tratar na unidade de saúde; desloca-se para o território, promovendo atenção na vida comunitária onde a população se insere (Silva e Dalmaso, 2004). Desse modo, os agentes entendem a importância do papel que desenvolvem na comunidade.

Nós somos o elo de ligação entre a comunidade e a unidade de saúde (Camélia).

A gente procura ajudar, e sempre que você ajuda alguém, você se sente recompensado (Chuva-de-prata).

As informações particulares sobre as condições ou agravos à saúde das famílias passam a ser reveladas e também observadas por esses profissionais, já que uma de suas atribuições peculiares refere-se à entrada nos domicílios dos usuários cadastrados na ESF (Seoane e Fortes, 2009). Essa relação de proximidade e confiança é percebida no relato seguinte:

Por mais que você seja o agente de saúde, mas para aquela família a gente é mais do que isso, porque eles confiam em contar os problemas deles. É como se a gente virasse um amigo. Eles não veem só o agente de saúde (Tulipa).

Entretanto, Silva e Dalmaso (2004) também apontam certo conflito na vivência desses profissionais. Eles garantem uma forte identificação com a comunidade da qual fazem parte, constituindo-se em trabalhadores singulares em saúde, contudo acabam formando um grupo próprio, por se diferenciarem dos demais membros da equipe. E os ACS confirmam isso em suas falas. Para eles, a categoria se distingue do restante da equipe, principalmente nos quesitos dedicação, compromisso e vínculo com a comunidade.

O lado positivo é esse, né? A gente se sentir útil, poder ajudar, poder fazer alguma coisa pela comunidade. Mas, por outro lado, a gente se sente decepcionada. Porque eu esperava mais da equipe (Rosa).

A gente tá tentando ficar grudada porque o restante da equipe é uma coisa que eles saem quase toda hora, aí já pensou se os agentes começarem a se debandiar [sic] também? Aí já é demais. A gente passa por um bocado de complicações ali e, às vezes, quer a ajuda do outro profissional, e nem sempre eles querem oferecer (Tulipa). 
A Política Nacional de Atenção Básica (Brasil, 2007) estabelece inclusive que o processo de preparação dos profissionais deve começar concomitantemente ao início do trabalho das equipes nos territórios adscritos da ESF. O município tem um prazo de três meses após a implantação da equipe para realizar o chamado Curso Introdutório. Entretanto, este curso ainda não é uma prática constante, apesar de sua relevância para o trabalho dos profissionais. Isso foi constatado no relato de um ACS recém-chegado na ESF.

Eu, como iniciante, eu tô querendo me adaptar ainda às dificuldades. (...) Porque assim que eu cheguei, se não fosse minhas colegas, eu não sabia o que eu tinha que fazer. Então, eu imaginava que primeiro iam me preparar. (...) Aqui, o agente chega e é jogado. Eu acho essa maneira errada (Violeta).

Aliás, desde o surgimento dessa categoria profissional, o ACS sempre suportou o 'peso' do excesso de tarefas e responsabilidades, gerado por expectativas depositadas pelos gestores, idealizando o projeto de reestruturação da saúde. Entretanto, as ações prioritárias desses sujeitos não emanam dos programas do Estado; são práticas inerentes aos problemas vividos e referidos pelas famílias em cada território com suas peculiaridades. O que parece é que o Estado sempre teve dificuldade em lidar com esse ator do ponto de vista educacional, já que se constata falha na interligação entre práticas e regimentos (Nogueira, 2002).

Outro ponto importante é que o papel do ACS vem sendo ampliado constantemente. Um estudo sobre o trabalho dos ACS nos Núcleos de Saúde da Família identificou uma nova atribuição a esse profissional. Acompanhando alunos de graduação de vários cursos da área de saúde e mesmo os profissionais que estão se inserindo na ESF, verifica-se que eles estão participando da formação de recursos humanos para a saúde da família (Lunardelo, 2004). $\mathrm{O}$ excesso de funções e a ampliação das atividades também se confirmam nos relatos.

Hoje a gente trabalha mais no controle, na prevenção. Nós trabalhamos mais do que qualquer outro profissional. Eu já conversei com algumas pessoas que, se nós não continuarmos esse serviço, nem médico, nem enfermeira, ninguém não tem como trabalhar (Cravo).

Tem gente que não quer levar o estudante pra área, pra ele não conhecer, não ver o trabalho que você desenvolve lá. Eu acho justamente o contrário. Eu mesmo faço questão de levar, apresentar, mostrar o trabalho que a gente tá fazendo (Jasmim).

Para os ACS, a essência de sua função constitui as relações estabelecidas tanto na comunidade quanto na equipe. Seu papel mediador é entendido 
como fundamental para a concretização das propostas da ESF (Vasconcellos e Costa-Val, 2008). Entretanto, se nesse relacionamento interno da equipe há uma inexistência de responsabilização coletiva pelos resultados dos trabalhos, pode ocorrer descontinuidade entre as ações específicas de cada profissional e desarticulação entre as ações educativas e curativas, gerando baixo grau de envolvimento entre eles (Pedrosa e Teles, 2001).

Os ACS entendem que a ESF ainda não funciona plenamente em sua essência. Há uma acomodação da equipe para as práticas ambulatoriais, o que provoca um distanciamento entre as ações realizadas pelos ACS e a atuação dos demais membros.

O PSF agora tá funcionando como ambulatório, né? A gente sabe que é pra tá mais na prevenção dos agravos, das doenças, e na verdade isso não tá acontecendo. Porque a gente não tem tempo pra fazer palestras, não tem tempo pra fazer alguma atividade educativa na área, com enfermeiro, com médico, com dentista... Se tirar a médica daqui de dentro no dia da consulta, a comunidade cai em cima da gente, porque quer é consulta, né? (...) A parte de prevenção mesmo só a que o agente de saúde faz, que é de porta em porta (Magnólia).

\section{A relação com a comunidade}

Nesta categoria, expõe-se como os ACS descrevem sua relação com a comunidade, os anseios desta para com o trabalho dos profissionais e as expectativas no sentido inverso, num espaço que pertence a ambos.

O fato de viver e intervir no processo saúde/doença, num nível de interação próprio de quem participa do mesmo espaço, com valores semelhantes, aproxima os ACS da comunidade. Essa interação gera uma relação de confiança entre as partes, contribuindo para as decisões que serão planejadas e executadas no processo de trabalho (Jorge et al., 2007). Essas afirmações foram constatadas pelo presente estudo, conforme a fala a seguir.

Quando a gente chega numa casa, a pessoa desabafa com a gente... tem aquela confiança (Papoula).

Esses profissionais conseguiram aliar na sua prática as dimensões 'saber-fazer' (domínio prático) e 'saber-conhecer' (domínio cognitivo), voltadas para atividades promocionais e preventivas, além de práticas de formação e fortalecimento dos sujeitos e comunidade, com características de educação popular em saúde e acompanhamento das famílias (Brasil, 2004). A disponibilidade para a escuta ativa e a troca de saberes entre agentes e comunidade é constante nos relatos. 
A gente não só repassa as informações que a gente sabe como a gente aprende muito com a população (Alfazema).

Entretanto, esse profissional se deparou com várias dificuldades presentes em seu processo de trabalho. A falta de entendimento da população sobre suas ações, confundindo com as práticas de outros profissionais, e limitações quanto à resolutividade dos problemas foram apenas algumas das barreiras encontradas durante todo esse tempo, como apontam Menegolla, Polleto e Krahl (2003).

Os achados da pesquisa corroboram essas afirmações. A ausência de compreensão da comunidade e, consequentemente, as cobranças enfrentadas pelos agentes são expostas pelos ACS.

A comunidade, às vezes a gente tá fazendo nosso trabalho, procurando ajudar, no que tá ao nosso alcance, e eles exigem mais e mais. Acham que a gente pode fazer além do que tá ao nosso alcance (Copo-de-leite).

A exigência de o ACS trabalhar e morar na mesma comunidade também gera diversos sentimentos, muitos deles decorrentes dos aspectos subjetivos presentes no cotidiano do seu trabalho. Ao mesmo tempo que promove vínculo, provoca invasão de privacidade do profissional. Isso faz com que o ACS acabe atuando durante 24 horas do dia, resultando, com grande frequência, em sofrimento psíquico para ele (Jardim, 2007). Essa situação se confirma no seguinte relato:

Dá 12 horas, você tá com a colher na mão pra almoçar, chega uma pessoa batendo na casa da gente. Aí aquilo ali, a gente tem que achar paciência pra receber, pra conversar, e aí eu acho até um desafio pra nós (Flor de caneleiro).

O ACS deve ter em mente, também, que a comunidade precisa ser corresponsabilizada e incentivar sua participação. É preciso partilhar, trocar, influenciar na tomada de decisões e ações, pois nenhum profissional trabalha sozinho, e a equipe de saúde não é a única responsável pelas ações de saúde (Brasil, 2009). Essa corresponsabilização começa a ser trabalhada pelos profissionais, estimulando a comunidade à participação ativa no processo.

Nesse negócio da população também não conseguir essas coisas e de certa forma eles também não se mobilizarem pra correr atrás de alguma coisa... Eu, no começo, eu não falava, mas ultimamente eu ando falando que eles têm que se unir, eles têm que correr atrás, porque muitas vezes só sabe vir aqui reclamar, aí termina quando eles não conseguem uma coisa aqui, eles desvalorizam totalmente o trabalho do agente... Só sobra mais é pra nós (Hortênsia). 


\section{Vantagens e desvantagens do trabalho em equipe}

Esta categoria traz o olhar dos ACS a respeito do trabalho coletivo: suas concepções sobre equipe, os benefícios dessa proposta de trabalho, as expectativas em relação a ela e as frustrações diante da atuação dos demais profissionais.

O trabalho em equipe deve ser concebido numa perspectiva de interação entre os diversos profissionais e também os usuários, promovendo a troca de saberes, fundamental no processo de construção e implementação das práticas (Brasil, 2008a). Os benefícios do trabalho em equipe são apontados pelos ACS participantes do estudo.

A gente nunca está sozinho, você tem sempre alguém que você pode contar, compartilhar, pedir uma ajuda na hora que você precisar, e eu acho assim que a equipe tem que ser isso. Uma ajudando a outra (Chuva-de-prata).

A vantagem é que você tá aprendendo também tanto com seu colega, né? (Margarida).

Porém, experiências distintas como relacionamentos internos individualistas entre os membros da equipe revelam a inexistência de responsabilidade coletiva pelos resultados dos trabalhos, levando a uma descontinuidade entre o papel de cada profissional, observando-se uma desarticulação entre as ações desenvolvidas (Pedrosa e Teles, 2001). Essa fragmentação apontada pelos autores também é descrita pelos ACS, o que para eles dificulta a fluência do trabalho conjunto.

A falta de comunicação entre os membros, principalmente médico e enfermeiro. Só tem mais comunicação entre os agentes. Dentista fica à parte, nem participa da reunião. A gente só sabe do dentista quando ele quer fazer uma palestra, aplicação de flúor, coisa assim (Azaleia).

Para Ronzani e Silva (2008), a responsabilidade coletiva dos membros da equipe é fundamental para o planejamento e a efetivação do trabalho. Cabe ao ACS o esforço inicial de articulação e integração com a comunidade, mas o cuidado e o estabelecimento de vínculos são responsabilidades de toda a equipe (Mishima e Campos, 2003). Assim, quando há ausência de profissionais, isso também tem uma influência relevante no processo de trabalho da equipe, pois dificulta o andamento adequado da ESF (Freitas et al., 2007). O prejuízo dessa ausência e/ou rotatividade se confirma por meio dos relatos.

Sabe qual é o problema? (...) A nossa equipe já teve uns cinco médicos, já teve umas três enfermeiras, auxiliar de enfermagem foram três... Quebra um pouco essa sequência de trabalho (Girassol). 
Tomaz (2002) traz para reflexão a ideia de que o perfil e as atribuições do agente de saúde precisam estar claramente definidos, para que não haja uma distorção do seu papel. O ACS não é e não deve ser um super-herói. Os sujeitos participantes do estudo igualmente ratificam:

“Qualquer problema que venha a acontecer aqui, procure seu agente." Como se a gente fosse Deus. E na realidade não é... (Lírio).

O trabalho em equipe vai se constituindo no seu fazer do dia a dia. Precisa ser analisado e preservado, pois passa por momentos de dificuldades, de insatisfação. Os profissionais anseiam por essa atenção. A equipe também precisa ser cuidada para produzir cuidados (Fortuna, 2003). Para os agentes, ao mesmo tempo que cuidam, eles precisam ser cuidados.

Existem ocasiões que até alguns profissionais eles não se lembram que a gente é ser humano. A gente tem os nossos problemas, a gente adoece, tem as fraquezas da gente, mas, muitas vezes, isso não é levado em conta (Cravo).

\section{Interação entre gestão e equipe Saúde da Família}

Esta categoria traz o olhar dos ACS sobre o papel da gestão, a supervisão realizada com as equipes de Saúde da Família, o diálogo com esses sujeitos e como eles interferem no processo de trabalho da equipe.

Santos et al. (2011) afirma que muitas ações realizadas pelos agentes ainda estão centradas no enfoque curativo, com orientações voltadas principalmente para determinadas doenças. Há uma priorização ao assistencialismo. Rosa e Labate (2005) ratificam, inclusive, que ações exageradamente voltadas aos programas preestabelecidos empobrecem e sumarizam a ESF, pois o olhar não se amplia para as reais necessidades de saúde, não gerando impactos importantes para a qualidade de vida das pessoas.

É nítida a atenção voltada para esses programas, como mostram as falas a seguir. As ações são guiadas, quase que exclusivamente, pelas exigências que devem ser cumpridas.

Só o atendimento de hipertenso que tá funcionando (Papoula).

A gente tem que atingir uma meta... É só isso que eles querem. Números! (Anis).

A falta de apoio estrutural para o trabalho gera insatisfação nos profissionais (Pereira, Silva e Haikal, 2009). Os agentes de saúde percebem que seu trabalho fica prejudicado por não haver incentivos por parte dos 
gestores (Santana et al., 2009). O apoio da gestão é primordial para o desenvolvimento do trabalho na ESF. E as dificuldades apontadas pelos autores são comprovadas por meio das falas dos agentes.

Eu considero a falta de apoio, principalmente por parte do próprio gestor mesmo (Cravo).

Às vezes a gente se sente de mãos atadas porque a gente quer realizar algumas atividades e a Regional barra, sabe!? É como se jogasse um balde de água fria na gente. "Vocês têm que trabalhar dessa forma e pronto, acabou" (Magnólia).

A supervisão da equipe é produção de cuidados em distintas direções. O supervisor, a equipe e o supervisor do supervisor devem se cuidar mutuamente. O acolhimento da gerência em saúde é fundamental para estruturar o trabalho em saúde das equipes (Fortuna, 2003). Paschoal (2001, apud Kluthcovsky et al., 2007) enfatiza, igualmente, a importância da valorização da opinião do indivíduo para sua qualidade de vida.

Reforça-se, aqui, a relevância da escuta e do cuidado para com os profissionais, destacando-se o papel do supervisor. Este deve atuar como colaborador das equipes, já que representa o elo entre equipes e gestão, sendo porta-voz das necessidades e das fragilidades do grupo e apoiador na construção do trabalho (Fortuna, 2003). Entretanto, o papel desses sujeitos não tem ocorrido de acordo com os anseios dos profissionais. Há apenas uma atuação fiscalizadora e transmissora de tarefas, como mostra os relatos.

A supervisora vem aqui, (...) dá as ordens e vai embora... (Hortênsia).

A nossa supervisora falou coisas absurdas. (...) Porque ela falou que no nosso serviço a gente tinha que deixar o pessoal alienado a nós, (...) fazer com que a população dependa da gente (Acácia).

O Ministério da Saúde enfatiza a necessidade de qualificação de seus trabalhadores por meio da educação permanente, porque quando se problematiza o processo de trabalho, permite-se a troca, o movimento de ideias, compreensões e decisões, potencializando o crescimento coletivo dos profissionais (Brasil, 2008b). A problematização deve ter participação ativa daqueles que conhecem as particularidades do território em que estão inseridos. Entretanto, essa é uma barreira que ainda deve ser superada, como apontam os agentes.

Eu tenho que trabalhar com a comunidade do mesmo jeito que eu trabalho na minha casa. Assim, de deixar meus filhos completamente independentes de mim. 
A comunidade também acha o mesmo, de ensinar, de ajudar, mas que ela caminhe com os próprios pés dela. Agora, quando dá pra uma pessoa de nível superior falar um negócio desses que tem que deixar a comunidade dependente de você... Fiquei decepcionada! Qual é o estímulo que a gente tem? (Rosa).

\section{As (des)motivações do cotidiano do trabalho}

Esta categoria traz o processo de trabalho dos ACS, descrito pelas motivações e desmotivações do dia a dia, as expectativas do reconhecimento e da valorização do seu trabalho.

Diante da complexidade que exige o trabalho do ACS, reconhece-se que, como profissional de saúde, ele esteja suscetível a situações que o coloquem sob estresse. Entre os eventos que geram sobrecarga de trabalho para os ACS, estão salário, condições de trabalho, relacionamentos interpessoais e carga emocional (Wai, 2007). Corroborando o que diz o autor, algumas dessas situações foram verificadas por este estudo.

Quando eu comecei, eu tinha assim uma vontade muito grande de trabalhar com a comunidade. Mas devido à falta de condições de trabalho, que eles não dão pra gente, e também a própria comunidade não enxergar o trabalho que a gente faz, eu tenho me sentido desestimulada (Lavanda).

Eu vejo muita cobrança, pra pouco dinheiro que nos é repassado (Girassol).

Muitos ACS também convivem com a frustração de suas limitações pessoais, tendo dificuldade por não resolver os problemas encontrados na comunidade, o que causa desmotivação e falta de comprometimento em seus trabalhos (Menegolla, Polleto e Krahl, 2003). Essa constatação aparece na fala a seguir:

Você chega na comunidade e a pessoa fica lhe pedindo coisas que você não pode alcançar. Desmotiva! (Girassol).

Quando não há o reconhecimento esperado pelos ACS, geram-se pressão e estresse, e às vezes pode até mesmo chegar a extremos como agressões físicas e/ou verbais (Pereira, Silva e Haikal, 2009). O desabafo seguinte representa de forma clara o que os autores mencionam em seu texto. Uma situação comum do dia a dia dos ACS e que causa desmotivação no trabalho desses profissionais.

Você se sente até impotente. Não podia ser assim, não! Porque na verdade seu trabalho não é pra você ser xingada, pra você ser humilhada. Porque todo trabalho tem 
seu valor. E o agente de saúde é a peça mais importante pro Programa Saúde da Família, porque sem o agente não funciona. E o médico não te valoriza, nem o enfermeiro, nem ninguém. Então, isso aqui é um desabafo [lágrimas e silêncio] (Amor-perfeito).

Para Reis (2005), o mal-estar sentido pelos ACS em relação à equipe tem como fonte a falta de reconhecimento pelo trabalho que desempenham com dedicação e esforço, o que afeta diretamente a sua saúde. Para a autora, não é o trabalho em si que gera sofrimento, mas sim o meio/condições em que esse trabalho se dá. Há um anseio dos agentes de saúde pelo reconhecimento de sua identidade profissional, o que se fosse atendido contribuiria, certamente, para a diminuição da instabilidade da classe na Saúde da Família (Nascimento, 2005). A importância do reconhecimento do trabalho, trazida por esses autores, é reforçada pelas falas dos ACS.

O nosso trabalho, eu acho assim que ele não é reconhecido como deveria ser. Não é reconhecido, eu não falo nem em termos de salário. Eu acho mesmo o reconhecimento do valor que é esse trabalho, né? Do que ele representa. (...) O agradecimento que eu digo não é nem por parte da comunidade, não. É por parte mesmo das pessoas que fazem a equipe. Não é porque a gente queira glória, não, é porque é bom a gente ser reconhecido (Jasmim).

Quando aparece alguma coisa pra ser feita, "entrega pro agente que ele faz". Sempre que tem um trabalho, "não, o agente sabe, o agente conhece". Mas na hora do reconhecimento, do agradecimento... (Açucena).

Ressalta-se a importância da qualificação e da profissionalização para esses trabalhadores, já que geram satisfação pessoal e profissional, contribuindo para a construção de sua identidade (Lunardelo, 2004). Igualmente, os sujeitos deste estudo apontam a importância da qualificação para eles. Contribui para o bom desenvolvimento do trabalho e, também, para o profissional se sentir valorizado.

A capacitação para os agentes. A gente já tá muito defasado de muita coisa, assim, porque faz muito tempo que a gente não é chamada pra fazer curso, capacitação, direcionado pro trabalho da gente. Fica sem saber muita coisa. Deixa de fazer, até por conta de não tá capacitado pra fazer aquela coisa (Jasmim).

Toda vez que a gente é capacitada, dá um fôlego novo. (...) E é bom porque tu tem [sic] outro conhecimento lá, pra adquirir algo novo (Azaleia).

Assim, se o mundo do trabalho é gerador de sofrimento, ele também pode ser uma oportunidade de crescimento e desenvolvimento para o indivíduo 
(Jardim e Lancman, 2009). É de suma importância que o valor do trabalho desses profissionais seja reconhecido, fortalecendo a responsabilidade do caráter transformador que a ESF tem em modificar o modelo da Atenção Básica vigente (Bornstein e Stotz, 2009).

O que motiva é exatamente isso, a gente poder fazer alguma coisa, poder ajudar, mesmo a duras penas, recebendo reclamações, recebendo, não, mas a gente tenta fazer de todas as maneiras, fazer com que dê certo, né? (Rosa).

\section{Considerações finais}

O estudo mostrou que, para os ACS, a valorização é importante para se sentirem motivados no trabalho. Anseia-se pelo reconhecimento do esforço e do empenho em contribuir positivamente naquilo que lhes foi designado. Valorizar provoca boas sensações nas pessoas, estimula, motiva a continuar e, principalmente, a melhorar.

Percebeu-se, igualmente, que a valorização e o reconhecimento, mencionados por eles, podem se manifestar de várias formas: pela definição explícita de suas atribuições; pela reciclagem no trabalho, com capacitações, treinamentos e outras atividades; pelo fato de ter a equipe como apoio, complementando e auxiliando em suas ações; pelo suporte necessário da gestão, tendo a equipe como parceira; ou mesmo pela importância de se ouvir um simples 'obrigado' da comunidade, dos membros da equipe e/ou da gestão.

A educação permanente em saúde é uma estratégia viável que permite problematizar o serviço com os profissionais, seus olhares sobre o trabalho, incluindo os produtos das relações em equipe e os problemas encontrados na comunidade e no processo como um todo. Como afirma Fortuna (2003, p. 17), "é preciso que a equipe de saúde seja cuidada para que possa produzir cuidados". O conjunto precisa se fortalecer e se sentir fortalecido.

O trabalho não é tão fácil nem tão simples quanto pode parecer essas entrelinhas, mas ratifica-se a importância de que todos devam estar disponíveis nessa construção. A saúde e a Estratégia Saúde da Família só irão melhorar com a disponibilidade e o envolvimento de todos. Os ACS são apenas uma parte desse conjunto, mas são elementos extremamente relevantes nessa caminhada.

Desse modo, espera-se que os achados desta pesquisa contribuam para futuras reflexões dos diversos atores, equipes, comunidade e gestores sobre a importância da valorização, subsidiem questionamentos a respeito das estratégias de motivação e revalorização dos ACS e, também, que proponham mudanças e coloquem em prática ações reconhecedoras do trabalho desses profissionais. 


\section{Notas}

1 Enfermeira. Especialista em Saúde da Família pelo Programa Residência Multiprofissional em Saúde da Família e Comunidade (RMSFC) da Universidade Estadual do Piauí (Uespi).<elainemcosta@hotmail.com>.

Correspondência: Conjunto Milton Oliveira, Quadra A, casa 15, CEP 64009-335, Memorare, Teresina, Piauí, Brasil.

2 Odontóloga, tutora do Programa Residência Multiprofissional em Saúde da Família e Comunidade (RMSFC) da Universidade Estadual do Piauí (Uespi), Teresina, Piauí, Brasil. Mestre em Ciências da Saúde pela Universidade Federal do Piauí (Uespi). < danyege@hotmail.com>.

\section{Referências}

BORNSTEIN, Vera Joana; STOTZ, Eduardo Navarro. O trabalho dos agentes comunitários de saúde: entre a mediação convencedora e a transformadora. Trabalho, Educação e Saúde, Rio de Janeiro, v. 6, n. 3, p. 457-480, nov.2008/fev.2009. Disponível em: <www.revista.epsjv.fiocruz.br/upload/ revistas/r220.pdf $>$. Acesso em: 4 set. 2009.

BRASIL. Ministério da Saúde. Conselho Nacional de Saúde. Resolução n. 196/96 sobre pesquisa envolvendo seres humanos. Brasília: Ministério da Saúde, 1996. Disponível em: <www.unb.br/fs/clm/labcor/ etic196.htm>. Acesso em: 4 set. 2009.

- Ministério da Saúde. Saúde da Família: uma estratégia para a reorientação do modelo assistencial. Brasília: Ministério da Saúde, 1997. Disponível em: < http://bvsms. saude.gov.br/bvs/publicacoes/cd09_16.pdf>. Acesso em: 1 jun. 2010.

Ministério da Saúde. Ministério da Educação. Referencial curricular para curso técnico do agente comunitário de saúde. Brasília: Ministério da Saúde, 2004. (Série A. Normas e Manuais Técnicos). Disponível em: <http://bvsms.saude.gov.br/bvs/publicacoes/ referencial_Curricular_ACS.pdf>. Acesso em: 27 set. 2009.

Ministério da Saúde. Secretaria de Atenção à Saúde. Departamento de Atenção Básica. Política nacional de Atenção Básica. 4. ed. Brasília: Ministério da Saúde, 2007.

Ministério da Saúde. Secretaria de Gestão do Trabalho e da Educação na Saúde. Departamento de Gestão da Educação na Saúde. Curso de formação de facilitadores de educação permanente em saúde: unidade de aprendizagem análise do contexto da gestão e das práticas de saúde. 2. ed. Rio de Janeiro: Ministério da Saúde/Fiocruz, 2008 .

Ministério da Saúde. Secretaria de Gestão do Trabalho e da Educação na Saúde. Departamento de Gestão da Educação na Saúde. Curso de formação de facilitadores de educação permanente em saúde: unidade de aprendizagem trabalho e relações na produção do cuidado em saúde. 2. ed. Rio de Janeiro: Ministério da Saúde/Fiocruz, 2008b. 
Ministério da Saúde. Secretaria de Atenção à Saúde. Departamento de Atenção Básica. O trabalho do agente comunitário de saúde. Brasília: Ministério da Saúde, 2009. Série F. Comunicação e Educação em Saúde. Disponível em: <http://dab.saude. gov.br/docs/publicacoes/geral/manual_acs. pdf>. Acesso em: 29 mai. 2010.

Ministério da Saúde. Secretaria de Atenção à Saúde. Departamento de Atenção Básica. Atenção Básica e a Saúde da Família. 2011. Disponível em: <http://dab. saude.gov.br/atencaobasica.php\#acs>. Acesso em: 16 ago. 2011.

CRUZ NETO, Otávio; MOREIRA, Marcelo Rasga; SUCENA, Luiz Fernando Mazzei. Grupos focais e pesquisa social qualitativa: o debate orientado como técnica de investigação. In: ENCONTRO DA ASSOCIAÇÃO BRASILEIRA DE ESTUDOS POPULACIONAIS, 13., Belo Horizonte, nov. 2002. Disponível em: <www.abep.nepo.unicamp.br/ docs/anais/pdf/2002/Com_JUV_PO27_Neto_ texto.pdf $>$. Acesso em: 24 set. 2009.

FORTUNA, Cinira Magali. Cuidando de quem cuida: notas cartográficas de uma intervenção institucional na montagem de uma equipe de saúde como engenhoca-mutante para produção da vida. Tese (Doutorado em Enfermagem de Saúde Pública) - Escola de Enfermagem de Ribeirão Preto, Universidade de São Paulo, 2003. Disponível em: <www.teses.usp.br/teses/disponiveis/22/ 22133/tde-31032005-114033/>. Acesso em: 9 jun. 2010.

FREITAS, Alexandra Corrêa et al. Desvelando a vivência de uma equipe multiprofissional de residentes em Saúde da Família com o agente comunitário de saúde. 2007. Revista APS, Juiz de Fora, v. 10, n. 2, p. 143-155, jul./dez., 2007. Disponível em: <http://www.ufjf.br/nates/files/2009/12/ 07desvelando.pdf $>$. Acesso em: 9 jun. 2010.

GIL, Antônio Carlos. Como elaborar projetos de pesquisa. 4. ed. São Paulo: Atlas, 2009.
JARDIM, Tatiana de Andrade. Morar e trabalhar na mesma comunidade: a realidade dos agentes comunitários de saúde. Dissertação (Mestrado em Ciências da Reabilitação) - Faculdade de Medicina, Universidade de São Paulo, 2007. Disponível em: $<$ www.teses.usp.br/teses/disponiveis/5/ 5163/tde-11122007-161633/>. Acesso em: 25 set. 2009.

JARDIM, Tatiana de Andrade; LANCMAN, Selma. Aspectos subjetivos do morar e trabalhar na mesma comunidade: a realidade vivenciada pelo agente comunitário de saúde. Interface - Comunicação, Saúde, Educação, Botucatu, v. 13, n. 28, p. 123-135, jan./mar.2009. Disponível em: <www.scielo. br/pdf/icse/v13n28/v13n28al1.pdf>. Acesso em: 6 set. 2009 .

JORGE, Maria Salete Bessa et al. Concepções dos agentes comunitários de saúde sobre sua prática no Programa de Saúde da Família. Revista APS, Juiz de Fora, v. 10, n. 2, p. 128-136, out.2007. Disponível em: $<$ http://www.ufjf.br/nates/files/2009/12/ 05 concepcao.pdf $>$. Acesso em: 6 set. 2009.

LUNARDELO, Simone Renata. O trabalho do agente comunitário de saúde nos núcleos de saúde da família em Ribeirão Preto. Dissertação (Mestrado em Enfermagem em Saúde Pública) - Escola de Enfermagem de Ribeirão Preto, Universidade de São Paulo, Ribeirão Preto, SP, 2004. Disponível em: $<$ www.teses.usp.br/teses/disponiveis/22/ 22133/tde-25062004-121856/>. Acesso em: 4 out. 2009.

MENEGOLLA, Vera Lúcia; POLLETO, Denise Sain; KRAHL, Mônica. O agente comunitário de saúde no desenvolvimento de seu trabalho. Boletim da Saúde, Porto Alegre, v. 17, n. 2, jul./dez.2003. Disponível em: <www.esp.rs. gov.br/img2/v17n2_12agenteComunitario. pdf>. Acesso em: 6 set. 2009.

MINAYO, Maria Cecília de Souza. Pesquisa social: teoria, método e criatividade. 22. ed. Petrópolis, RJ: Vozes, 2003. 
MISHIMA, Silvana Martins; CAMPOS, Ana Cláudia. O trabalho no Programa Saúde da Família: perfil das equipes. REME - Revista Mineira de Enfermagem, Belo Horizonte, v. 7, n. 2, p. 124-133, 2003. Disponível em: $<$ http://bases.bireme.br/cgi-bin/wxislind.exe/ iah/online/?IsisScript=iah/iah $\cdot \mathrm{xis} \& \operatorname{src}=$ google\&base $=$ LILACS\&lang $=$ p\&nextAction $=$ lnk\&exprSearch=479301\&indexSearch=ID $>$. Acesso em: 9 jun. 2010.

MOYSÉS, Samuel Jorge et al. A equipe de saúde multiprofissional nos programas de Saúde da Família. Revista Médica do Paraná, Curitiba, v. 57, no 1-2, p. 1-7, 1999. Disponível em: <http://bases.bireme.br/ cgi-bin/wxislind.exe/iah/online/?IsisScript= iah/iah. $x i s \& s r c=$ google $\&$ base $=$ LILACS $\&$ lang $=$ $\mathrm{p} \&$ nextAction $=\operatorname{lnk} \& \operatorname{exprSearch}=277598 \&$ indexSearch=ID >. Acesso em: 6 set. 2009.

NASCIMENTO, Cynthia Maria Barboza do. Precarização do trabalho do agente comunitário de saúde: um estudo em municípios da região metropolitana do Recife. Recife, 2005. Disponível em: <http://www.cpqam.fiocruz.br/ observarh/publicacoes/arquivos/precarizacao_ acs_rmr.pdf $>$. Acesso em: 10 set. 2009.

NOGUEIRA, Roberto Passos. O trabalho do agente comunitário de saúde: entre a dimensão 'universalista' e a dimensão social 'comunitarista'. Interface - Comunicação, Saúde, Educação, Botucatu, v. 6, n. 10, p. 75-94, fev.2002. Disponível em: <www.interface. org. br/revista10/debates4.pdf $>$. Acesso em: 14 out. 2009.

KLUTHCOVSKY, Ana Cláudia G. C. et al. Avaliação da qualidade de vida geral de agentes comunitários de saúde: a contribuição relativa das variáveis sociodemográficas e dos domínios da qualidade de vida. Revista de Psiquiatria do Rio Grande do Sul, Porto Alegre, v. 29, n. 2, p. 177-183, 2007. Disponível em: <www.revistapsiqrs.org.br/ administracao/arquivos/29-02-09.pdf >. Acesso em: 9 jun. 2010.

PEDROSA, José Ivo dos Santos; TELES, João Batista Mendes. Consensos e diferenças em equipes do Programa Saúde da Família. Revista de Saúde Pública, São Paulo, v. 35, n. 3, p. 303-311, jun.2001. Disponível em: <http://www.fnepas.org.br/pdf/cobem07/ pedrosa_cobem_07.pdf $>$. Acesso em: 19 set. 2009.

PEREIRA, Cláudia Borges Borges; SILVA, Erivânia Cardoso; HAIKAL, Desirée Sant'Ana. Qualidade de vida de agentes comunitários de saúde: uma abordagem qualitativa. In: FÓRUM GESTÃO, PESQUISA, ENSINO, EXTENSÃO, 3., Montes Claros, 2009. Disponível em: <www.fepeg.unimontes.br/evento2009/ index.php/fepeg/fepeg2009/paper/viewFile/ 165/310 >. Acesso em: 9 jun. 2010.

REIS, Luciana Bicalho. Uma análise de dimensão ético-política do trabalho de agentes comunitários de saúde do município de Vitória. Dissertação (Mestrado em Psicologia) - Universidade Federal do Espírito Santo, Vitória, ES, 2005. Disponível em: <www. cchn.ufes.br/ppgp/download/dissertacoes/ 2005\%20-\%20Luciana\%20Bicalho\%20Reis. pdf $>$. Acesso em: 1 jun. 2010.

RONZANI, Telmo Mota; SILVA, Cristiane de Mesquita. O Programa Saúde da Família segundo profissionais de saúde, gestores e usuários. Ciência \& Saúde Coletiva, Rio de Janeiro, v. 13, n. 1, p. 23-34, 2008. Disponível em: <www.scielo.br/pdf/csc/v13nl/ 06.pdf>. Acesso em: 9 jun. 2010.

ROSA, Walisete de Almeida Godinho; LABATE, Renata Curi. Programa Saúde da Família: a construção de um novo modelo de assistência. Revista Latino-Americana de Enfermagem, Ribeirão Preto, SP, v. 13, n. 6, p. 1027-1034, nov.-dez.2005. Disponível em: $<$ www.scielo.br/pdf/rlae/v13n6/v13n6al6. pdf>. Acesso em: 9 jun. 2010.

SANTANA, Júlio César Batista et al. Agente comunitário de saúde: percepções na Estratégia Saúde da Família. Cogitare Enfermagem, Curitiba, v. 14, n. 4, p. 645-652, out./dez.2009. Disponível em: <http://ojs.c3sl.ufpr.br/ojs2/ index.php/cogitare/article/viewFile/16377/ 10858>. Acesso em: 9 jun. 2010. 
SANTOS, Karina Tonini dos et al. Agente comunitário de saúde: perfil adequado à realidade do Programa Saúde da Família? Ciência \& Saúde Coletiva, online, Rio de Janeiro, v. 16, supl. 1, p. 1023-1028, 2011. Disponível em: <www.scielosp.org/pdf/csc/v16sl/ a35v16s1.pdf $>$. Acesso em: 14 out. 2009.

SEOANE, Antônio Ferreira; FORTES, Paulo Antônio de Carvalho. A percepção do usuário do Programa Saúde da Família sobre a privacidade e a confidencialidade de suas informações. Saúde e Sociedade, São Paulo, v. 18, n. 1, p. 42-49, 2009. Disponível em: $<$ www.teses.usp.br/teses/disponiveis/6/6135/ tde-21082007-174021/>. <www.scielo.br/pdf/ sausoc/v18nl/05.pdf $>$. Acesso em: 9 jun. 2010.

SILVA, Joana Azevedo; DALMASO, Ana S. Whitaker. Agente comunitário de saúde: o ser, o saber, o fazer. Rio de Janeiro: Editora Fiocruz, 2002.

- Agente comunitário de saúde: o ser, o saber, o fazer. Cadernos de Saúde Pública, Rio de Janeiro, v. 20, n. 5, p. 1.4331.437, set./out.2004. Disponível em: $<$ www.scielosp.org/scielo.php?pid=S0102311 X2004000500041\&script=sci_arttext > . Acesso em: 6 set. 2009.

TOMAZ, José Batista Cisne. O agente comunitário de saúde não deve ser um 'superherói'. Interface - Comunicação, Saúde, Educação, v. 6, n. 10, p. 75-94, fev.2002. Disponível em: <www.scielo.br/pdf/icse/v6n10/ 08.pdf>. Acesso em: 14 out. 2009.
VASCONCELOS, Eymard Mourão. A priorização da família nas políticas de saúde. Revista Saúde em Debate, Rio de Janeiro, v. 23, n. 53, p. 6-19, set./dez., 1999. Disponível em: $<$ www.cebes.org.br/media/File/publicacoes/ Rev\%20Saude\%20Debate/Saude\%20em\% 20Debate_n53.pdf>. Acesso em: 23 set. 2011.

VASCONCELLOS, Natália de Paula Carneiro; COSTA-VAL, Ricardo. Avaliação da qualidade de vida dos agentes comunitários de saúde de Lagoa Santa-MG. Revista APS, v. 11, n. 1, p. 17-28, jan./mar.2008. Disponível em: $<$ www.ufjf.br/nates/files/2009/12/017-028. pdf $>$. Acesso em: 16 set. 2009.

VELLOSO, Isabela Silva Câncio. A interferência da violência social no trabalho em uma unidade básica de saúde. Dissertação (Mestrado em Enfermagem) - Escola de Enfermagem da Universidade Federal de Minas Gerais, Belo Horizonte, 2005. Disponível em: $<$ www.enf.ufmg.br/mestrado/dissertacoes/ IsabelaSilva.pdf $>$. Acesso em: 9 jun.2010.

WAI, Mey Fan Porfírio. O trabalho do agente comunitário de saúde na Estratégia Saúde da Família: fatores de sobrecarga e mecanismos de enfrentamento. Dissertação (Programa de Pós-Graduação em Enfermagem Psiquiátrica - Mestrado) - Ribeirão Preto. Escola de Enfermagem de Ribeirão Preto, Universidade de São Paulo, 2007. Disponível em: $<$ www.teses.usp.br/teses/disponiveis/22/ 22131/tde-08082007-104445/>. Acesso em: 6 set. 2009.

Recebido em 14/06/2011

Aprovado em 05/08/2011 